\title{
Low-dose methotrexate treatment in severe glucocorticoid- dependent asthma: effect on mucosal inflammation and in vitro sensitivity to glucocorticoids of mitogen-induced T-cell proliferation
}

\author{
B. Vrugt*, S. Wilson**, A. Bron*, J. Shute**, S.T. Holgate**, R. Djukanovic*, R. Aalbers*
}

\begin{abstract}
Low-dose methotrexate treatment in severe glucocorticoid-dependent asthma: effect on mucosal inflammation and in vitro sensitivity to glucocorticoids of mitogen-induced T-cell proliferation. B. Vrugt, S. Wilson, A. Bron, J. Shute, S.T. Holgate, R. Djukanovic, R. Aalbers. C ERS Journals Ltd 2000.

ABSTRACT: The authors have investigated whether the steroid-sparing effect of methotrexate (MTX) in severe orally glucocorticoid-insensitive asthmatics may be accounted for by the ability of this drug to increase the T-cell responsiveness sensitivity to dexamethasone in vitro. In addition the authors have investigated whether low-dose MTX treatment is associated with anti-inflammatory effects in peripheral blood and the bronchial mucosa.

In eight patients with severe atopic asthma, using $\geq 15 \mathrm{mg} \cdot$ day $^{-1}$ prednisolone, the inhibitory effect of dexamethasone on mitogen stimulated peripheral blood mononuclear cells (PBMC) in vitro was tested before and after 8 weeks of uncontrolled treatment with MTX. Endobronchial biopsies were taken before and after MTX therapy in seven subsequent patients, and analysed using immunohistochemistry. In eight patients, serum was drawn for measuring levels of free interleukin (IL)-8.

The in vitro sensitivity of PBMC to dexamethasone (at $1.6 \times 10^{-9}$ and $3.2 \times 10^{-10}$ mol $\cdot \mathrm{L}^{-1}$ ) was significantly lower in the asthmatics before treatment when compared with the control subjects $(p=0.03$ and $=0.001)$ but increased significantly after MTX treatment $(p=0.04$ and $=0.02)$ to normal responsiveness. This was not associated with a decrease in peripheral blood T-cell numbers or activation. Except for a significant increase in the numbers of $\mathrm{CD3}+(\mathrm{p}=0.04)$, no significant numerical changes in activated T-cells, eosinophils, or mast cells were found $(p>0.05)$. However, MTX treatment was associated with a significant fall in serum levels of free IL-8 $(p=0.03)$.

It is hypothesized that the steroid-sparing effect of methotrexate originates from increased sensitivity of lymphocytes to the inhibitory effects of glucocorticoids. The absence of an inhibitory effect on inflammatory cells in blood and mucosa suggests that this effect is achieved by modulating cell function rather than cell number.

Eur Respir J 2000; 15: 478-485.
\end{abstract}

\begin{abstract}
*Martinihospital, Groningen, the Netherlands. **Immunopharmacology group, Medicine I, Southampton University, Southampton, UK. "Dutch Asthma Centre, Davos, Switzerland.
\end{abstract}

Correspondence: B. Vrugt

Martini Hospital Groningen

Pathology Department

P.O. Box 30033

9700 RM Groningen

The Netherlands.

Fax: 31505245759

Keywords: Glucocorticoids

interleukin-8

methotrexate

severe asthma

Received: June 201999

Accepted after revision November 251999
Airway inflammation in bronchial asthma is characterized by increased numbers of activated T-cells, eosinophils and mast cells in the airways. The extent of mucosal inflammation is considered to play a major role in the clinical presentation of the disease [1]. Glucocorticoids are the most potent anti-inflammatory drugs currently available and numerous studies have shown their clinical efficacy in the management of asthma [2]. Although the mechanisms by which glucocorticoids reduce airway inflammation are not fully understood, their clinical effect is thought to result from inhibition of T-cell activation, eosinophil recruitment and activation [2], and suppression of cytokine release by activated T-cells [3].

Despite the beneficial effects of glucocorticoids in most patients, a minority of patients continue to have severe symptoms requiring the institution of systemic glucocorticoids which places them at risk of developing considerable side effects, such as osteoporosis, peptic ulcers, Cush- ingoid appearance, suppression of the adrenal glands, and in children, growth retardation. A proportion of these patients is found to be relatively resistant to the anti-inflammatory effects of glucocorticoids as judged by the reduced suppressive effects of dexamethasone on the proliferative response of peripheral blood mononuclear cells (PBMC) to the mitogen phytohaemagglutinin (PHA) [4] and increased peripheral blood T-cell activation [5]. Recently the authors have extended these observations to the bronchial mucosa by demonstrating the existence of increased mucosal T-cell activation in severe glucocorticoid-dependent asthmatics as compared to mild asthma and healthy control subjects [6]. In addition, increased concentrations of free interleukin (IL)-8 have been found in serum of severe asthmatics who were dependent on high doses of inhaled and in most cases systemic glucocorticoids [7].

Of greater clinical importance is that while glucocorticoid-insensitive asthma is associated with refractoriness to 
glucocorticoids, patients with severe asthma may benefit from treatment with other potentially anti-inflammatory drugs, such as cyclosporin-A [8] and methotrexate (MTX) [9]. MTX has been used in low doses for almost a decade in the management of severe glucocorticoid-dependent asthma with the primary goal of reducing the glucocorticoid requirements. Several reports have shown that the addition of MTX to glucocorticoid therapy allowed for lower glucocorticoid requirements while maintaining asthma control [10-13].

Most of the present knowledge about the anti-inflammatory effects of low-dose MTX originates from studies on subjects with rheumatoid arthritis and psoriasis [14, 15]. These have shown that MTX modulates cell function without affecting the number of leukocytes at sites of inflammation $[16,17]$. In asthma, it is generally accepted that MTX has anti-inflammatory properties, but the mechanism whereby MTX reduces the need for glucocorticoid therapy and diminishes mucosal inflammation have not yet been investigated. In order to improve understanding of the anti-inflammatory mechanisms of MTX of relevance to asthma the authors have studied a group of 15 severe glucocorticoid-dependent asthmatics before and after 8-weeks treatment with this drug.

\section{Subjects and methods}

\section{Patients}

Fifteen patients aged 13-50 yrs (table 1) who fulfilled the diagnostic criteria of atopic bronchial asthma according to the American Thoracic Society [18] and had spontaneous or pharmacologically induced reversibility of at least $15 \%$ in peak expiratory flow (PEF) or forced expiratory volume in one second (FEV1) were enrolled. All had required long-term maintenance treatment with oral prednisolone for $>1$ yr at a minimum dose of 15 $\mathrm{mg} \cdot \mathrm{day}^{-1}$ in addition to regular treatment with bronchodilators (at least four doses of salbutamol per day by

\begin{tabular}{cccccc}
\multicolumn{6}{c}{ Table 1. - Subjects characteristics } \\
\hline & Sex & $\begin{array}{c}\text { Age } \\
\text { yrs* }\end{array}$ & $\begin{array}{c}\text { FEV1 } \\
\text { \% predicted }\end{array}$ & $\begin{array}{c}\text { Inhaled } \\
\text { GCS* }\end{array}$ & $\begin{array}{c}\text { GCS before } \\
\text { MTX* }^{*}\end{array}$ \\
\hline 1 & M & 39 & 48 & 2.4 & 20 \\
2 & $\mathrm{~F}$ & 20 & 63 & 2 & 20 \\
3 & $\mathrm{M}$ & 34 & 73 & 2 & 50 \\
4 & $\mathrm{M}$ & 50 & 49 & 2 & 20 \\
5 & $\mathrm{~F}$ & 50 & 73 & 2.4 & 15 \\
6 & $\mathrm{~F}$ & 19 & 59 & 2.4 & 30 \\
7 & $\mathrm{~F}$ & 15 & 41 & 3 & 60 \\
8 & $\mathrm{~F}$ & 18 & 45 & 2.4 & 20 \\
9 & $\mathrm{~F}$ & 13 & 37 & 1.8 & 100 \\
10 & $\mathrm{~F}$ & 17 & 64 & 2 & 60 \\
11 & $\mathrm{~F}$ & 25 & 82 & 4 & 30 \\
12 & $\mathrm{~F}$ & 15 & 53 & 2 & 60 \\
13 & $\mathrm{~F}$ & 23 & 56 & 4 & 50 \\
14 & $\mathrm{~F}$ & 24 & 48 & 4 & 50 \\
15 & $\mathrm{M}$ & 48 & 56 & 3.2 & 40 \\
& & $23(13-50)$ & $56.5 \pm 12.7$ & $2.4(1.8-4)$ & $40(15-100)$ \\
\hline
\end{tabular}

*: mg.day ${ }^{-1}$, expressed as median (range) ${ }^{+}$: per cent of predicted, expressed as mean \pm SD. FEV1: forced expiratory volume in one second; GCS: glucocorticoids; MTX: methotrexate; M: male; F: female. nebulizer and/or metered dose inhaler) and high doses of inhaled glucocorticoids $\left(>1,600 \mu \mathrm{g} \cdot \mathrm{day}^{-1}\right)$. The patients were hospitalized in the Dutch Asthma Centre in Davos, Switzerland, because of unsatisfactory control of their asthma with nightly episodes of wheezing and frequent exacerbations. In all patients glucocorticoid treatment was associated with Cushingoid features. Each patient was followed closely for the presence of unidentified allergies and potential aggravating factors such as gastrooesophageal reflux, nasal polyps, sinusitis, and drug intolerance.

Exclusion criteria were pregnancy or lack of adequate contraception, renal dysfunction, hepatic disease, or haematological disorders. Patients with a history of alcohol or tobacco abuse, or a current history of obesity (body weight $>50 \%$ over normal for age and height), poor medical compliance, diabetes mellitus, interstitial lung disease, or recent asthma exacerbations (within 1 month prior to the study) were also excluded.

The study was approved by the Ethical Committee of the Dutch Asthma Centre and all subjects gave their written informed consent. In minors consent was given by the parents.

\section{Study design}

The study was conducted over 18 weeks and consisted of two phases. During a 10 week run-in period patients were maintained on the lowest dose of oral prednisolone required to prevent exacerbations. At least two attempts were made to reduce the dose of glucocorticoids. Then all patients received MTX once a week $\left(15 \mathrm{mg} \cdot\right.$ week $^{-1}$ i.m. $)$ during a period of 8 weeks while all other medication, including inhaled and oral glucocorticoids, were kept constant. In all patients blood was drawn for flow cytometric analyses before and after MTX treatment. In addition, PBMC from 8 patients were isolated for in vitro proliferation inhibition assay before and after the treatment trial. The results from this part of the study prompted the authors to take endobronchial biopsies by fibreoptic bronchoscopy before and after MTX in a subsequent group of seven severe asthmatics. They were reviewed twice a week by the same physician to evaluate the clinical status and side effects of treatment.

\section{Clinical and physiological measurements}

Subjects recorded PEF twice daily before and after bronchodilator medication using a mini Wright peak flow meter (Airmed, London, UK). Variability in PEF, an indicator of airways irratibility, was calculated by the difference between the maximum and minimum of the four PEF results each day and expressed as a percentage of the maximum [19]. The mean value of seven calculations each week was used for statistical analysis. In addition, subjects were asked to record their daily use of salbutamol as the number of puffs delivered via dose inhaler and the frequency of use of nebulized salbutamol. Lung function tests were performed before, and 4 and 8 weeks after commencing MTX and consisted of prebronchodilator FEV1, forced vital capacity (FVC), whole body plethysmography and carbon monoxide diffusing capacity of the lung $(D \mathrm{~L}, \mathrm{CO})$ 
using a pneumotachometer (Jaeger Masterlab, Würzburg, Germany). Values were expressed as a percentage of predicted.

\section{Blood analyses}

Blood was drawn before, and after 4 and 8 weeks of MTX treatment. Analyses consisted of full blood count with differential counts. Blood biochemistry analyses included measurements of serum creatinine and urea, liver function tests (serum aspartate aminotransferase and alkaline phosphatase), and total immunoglobulin (Ig)E. In eight patients serum was collected before and after treatment with MTX to determine its effect on levels of free IL8 using a sandwhich-enzyme linked immunosorbent assay (ELISA) as previously described [7]. Briefly IL-8 was quantified using a solid-phase double-ligand ELISA in which free IL- 8 is captured by a specific monoclonal antibody. ELISA plates were read at $410 \mathrm{~nm}$ on MR 5000 plate reader (Dynatech Laboratories, Billinghurst, UK). IL-8 concentrations were calculated with reference to a standard curve constructed using human recombinant (hr)-IL-8 over a range of $20 \mathrm{pg} \cdot \mathrm{mL}^{-1}$ to $10 \mathrm{ng} \cdot \mathrm{mL}^{-1}$.

\section{Flow cytometry}

Flow cytometric analyses of peripheral blood cells from all subjects with severe asthma and eight nonatopic, nonasthmatic individuals (four females, four males, aged 1842 yrs) were performed before and after treatment using monoclonal antibodies against CD3 (total T-cells), CD4 (helper/inducer T-cells), and CD8 (suppressor/cytotoxic Tcells), CD25 (IL-2 receptor; IL-2R) and human leukocyte antigen (HLA)-DR (major histocompatibility complex (MHC)-class II molecule) for activated T-cells (Immunotech, Marseille, France), and CD19 (total B cells) and low affinity Fc RII (CD23) (Becton Dickinson, Mountain View, CA, USA). Analysis was performed with scatter gates on the lymphocyte fraction using laser excitation at $488 \mathrm{~nm}$ and analysing a total of 10,000 events.

\section{Lymphocyte proliferation inhibition assay}

The ability of dexamethasone to suppress lymphoproliferative responses to PHA as an indicator of T-cell responsiveness to glucocorticoids before and after treatment with MTX was studied in eight asthmatics. PBMC were separated by Ficoll-Hypaque density centrifugation (Pharmacia Fine Chemicals, Sweden) from blood taken $24 \mathrm{~h}$ after the last dose of prednisolone. For comparison PBMC from the eight control subjects were isolated and analysed at the same time. Blood was diluted with phosphate buffered saline (PBS), layered on Ficoll and centrifuged for 20 $\mathrm{min}$ at $800 \times \mathrm{g}$. The layer of PBMC was collected, washed twice in PBS and resuspended in Roswell Park Memorial Institute medium (RPMI)-1640 enriched with $10 \%$ foetal calf serum (FCS). Cell density was adjusted to $1 \times 10^{6}$ cells $\cdot \mathrm{mL}^{-1}$. For ${ }^{3} \mathrm{H}$-thymidine incorporation assays, PBMC were cultured in microculture plates (Falcon Plastics, Oxnard, CA, USA) in triplicate. The following compositions were used: $100 \mu \mathrm{L}$ of cell suspension, $50 \mu \mathrm{L}$ of PHA $(0.5$ $\mu \mathrm{L} \cdot \mathrm{mL}^{-1}$ ) and $50 \mu \mathrm{L}$ of dexamethasone (Sigma Chemical $\mathrm{Co}$, St. Louis, MO, USA) at concentrations of $1.0 \times 10^{-6}$,
$2.0 \times 10^{-7}, 4.0 \times 10^{-3}, 8.0 \times 10^{-9}, 1.6 \times 10^{-9}$, and $3.2 \times 10^{-10}$ M. After $24 \mathrm{~h}$ of incubation at $37^{\circ} \mathrm{C}$ in $5 \% \mathrm{CO}_{2}, 20 \mu \mathrm{L}^{3} \mathrm{H}$ thymidine $\left(1 \mu \mathrm{Ci} \cdot \mathrm{mL}^{-1}\right.$; Amersham, Cambridge, UK) were added. After $6 \mathrm{~h}$ of incubation, cells were harvested (Skatron, Lierbyen, Norway) and the incorporated radioactivity determined in a liquid scintillation counter (Betaplate; Pharmacia, Uppsala, Sweden).

\section{Fibreoptic bronchoscopy and tissue analyses}

Fibreoptic bronchoscopy was performed in seven subjects with severe asthma before and after phase 2. Biopsies were taken of the subcarinae of the right middle and lower lobes according to previous published methods [20, 21]. Specimens were then processed into glycol methacrylate (GMA) resin for immunohistochemistry, as previously described [22]. Two-micrometre sections were cut and immunohistochemical staining performed using the following monoclonal antibodies: AA1 (directed against tryptase) for mast cells, EG2 (Pharmacia, Milton Keynes, UK; directed against the cleaved form of eosinophilic cationic protein) for eosinophils, anti-neutrophil elastase (NE) (Dako, High Wycombe, Buckinghamshire, UK) for neutrophils, anti-CD3 (Dako) for total T-cells, anti-CD4 (Becton Dickinson, Abingdon, Oxfordshire, UK) for helper/inducer T-cells, anti-CD8 (Dako) for suppressor/ cytotoxic T-cells, and anti-CD25 (Dako) for IL-2R bearing cells. Because IL-2R can be found on activated Tcells, eosinophils, monocytes and B-cells, adjacent $2-\mu \mathrm{m}$ thick sections were stained with cell-specific antibodies and anti-CD25 antibody. Using the camera lucida method [23] CD25-positive staining was colocalized with cell specific staining. To assess possible effects of MTX on IL-4, the authors have employed monoclonal antibodies 4D9 and 3H4 (donated by C. Heusser, Ciba, Basel, Switzerland) shown previously to distinguish between intracellular and secretory IL-4 [23]. For IL-5 the authors have used Mab-7 (L.A. McNamee, Glaxo, Greenford, Middlesex, UK) to detect cellular IL-5 [24].

The stained sections were coded and examined by a single-blinded investigator (B. Vrugt). Only positively stained, nucleated cells were counted at $\times 40$ magnification. The area of the submucosa was measured using the Colourvision 1.6-4SR software package on a Macintosh computerized image analyzer (Improvision, Birmingham, UK) excluding the large blood vessels, smooth muscle, and glandular tissue. The total count of cells was expressed as the mean number of cells per square millimetre submucosa of two sections.

\section{Data analyses}

FEV1, FVC (\% of predicted) and PEF variability were expressed as mean \pm SD. Differences in lung function results within groups were analysed using the paired t-test. Proliferation inhibition by different concentrations of dexamethasone was expressed as the percentage of maximum inhibition achieved by dexamethasone at a concentration of $10^{-6} \mathrm{M}$. In the asthmatics pretreatment values were compared with those after therapy using the Wilcoxon Signed Rank test. Differences between asthmatics and control subjects were analysed using the Mann-Whitney U-test. Cell counts from the tissue samples were expressed as medians 
(range) and the Wilcoxon Signed Rank test used to compare pre-with post-treatment values. Differences were considered significant if $\mathrm{p}<0.05$.

\section{Results}

\section{Study course}

There were two withdrawals from the study after 4 weeks of treatment: one was a 19-yr-old female (subject No. 7) who developed repeated asthma exacerbations after MTX was commenced requiring prolonged, high-dose prednisolone therapy, and the other was a 15-yr-old adolescent (subject No. 8; table 1) who developed intestinal pneumatosis. The post treatment values of these subjects were excluded from statistical analysis.

\section{Effect of methotrexate on clinical parameters}

In the overall group MTX treatment did not result in improvement of any of the clinical parameters determined during the study period (table 2).

Effect of methotrexate treatment on peripheral blood leukocyte- and lymphocyte subpopulations and activation

No significant treatment related changes were observed in mean $( \pm \mathrm{SEM})$ leukocyte counts $\left(10.6 \pm 1.5 \times 10^{9} \cdot \mathrm{L}^{-1}\right.$ before and $11.6 \pm 1.6 \times 10^{9} \cdot \mathrm{L}^{-1}$ after MTX) or the differential counts. Flow cytometric analyses revealed no significant changes in the mean $( \pm$ SEM) percentage of CD3+ T-cells $(72.3 \pm 2.6 \%$ before and $72.0 \pm 3.2 \%$ after MTX), CD4+ Tcells $(40.7 \pm 2.6 \%$ before and $42.5 \pm 3.3 \%$ after MTX) and CD8+ T-cells $(25.5 \pm 2.3 \%$ before and $23.1 \pm 1.6 \%$ after MTX); $>0.05$. Also no significant reduction was found in the expression of IL-2R on CD4+ T-cells $(4.6 \pm 0.6$ and $7.0 \pm 1.9 \%)$ and CD8+ T-cells $(0.9 \pm 0.3 \%$ and $1.2 \pm 0.3 \%)$ between baseline and after 8 weeks of MTX treatment ( $p>0.05)$. Similarly, the percentages of CD4/HLA-DR+ $(3.7 \pm 0.7 \%)$ and CD8/HLA-DR+ cells $(5.7 \pm 1.7 \%)$ before introduction of MTX were not significantly different from post-treatment values $(4.1 \pm 1.4$ and $4.0 \pm 0.6 \%$ respectively); $\mathrm{p}>0.05$.

Effect of methotrexate treatment on the in vitro sensitivity of peripheral blood mononuclear cells to dexamethasone

The PBMC obtained from the eight severe asthmatics showed decreased sensitivity to dexamethasone at con-

Table 2. - Summary of clinical data before and after methotrexate (MTX) treatment $(n=13)$

\begin{tabular}{lccc}
\hline & Before MTX & After MTX & p-value \\
\hline FEV1* $^{*}$ & $57.5 \pm 12.9$ & $66.9 \pm 25.5$ & 0.08 \\
FVC $^{*}$ & $86.8 \pm 13.9$ & $87.3 \pm 22.1$ & 0.82 \\
Mean morning PEF* $^{*}$ & $51.9 \pm 18.4$ & $59.8 \pm 21.8$ & 0.11 \\
PEF variability $^{+}$ & $27.8 \pm 12.9$ & $25.6 \pm 10.6$ & 0.42 \\
Symptom score $^{+}$ & $7(1.3-13)$ & $5.4(1-11.3)$ & 0.23 \\
\hline
\end{tabular}

*: per cent of predicted, expressed as mean $\pm \mathrm{SD} ;{ }^{+}$: per cent, expressed as mean $\pm \mathrm{SD} ; *$ mean value of seven calculations per week, expressed as median (range). centrations $1.6 \times 10^{-9}$ and $3.2 \times 10^{-10} \mathrm{M}$ before MTX in comparison to PBMC obtained from the healthy control subjects (fig. 1a). In the six asthmatics who completed the trial, 8 weeks of MTX treatment was associated with a significantly increased sensitivity of PBMC to the inhibitory effects of dexamethasone in vitro compared to pretreatment values (fig. 1b), such that no significant
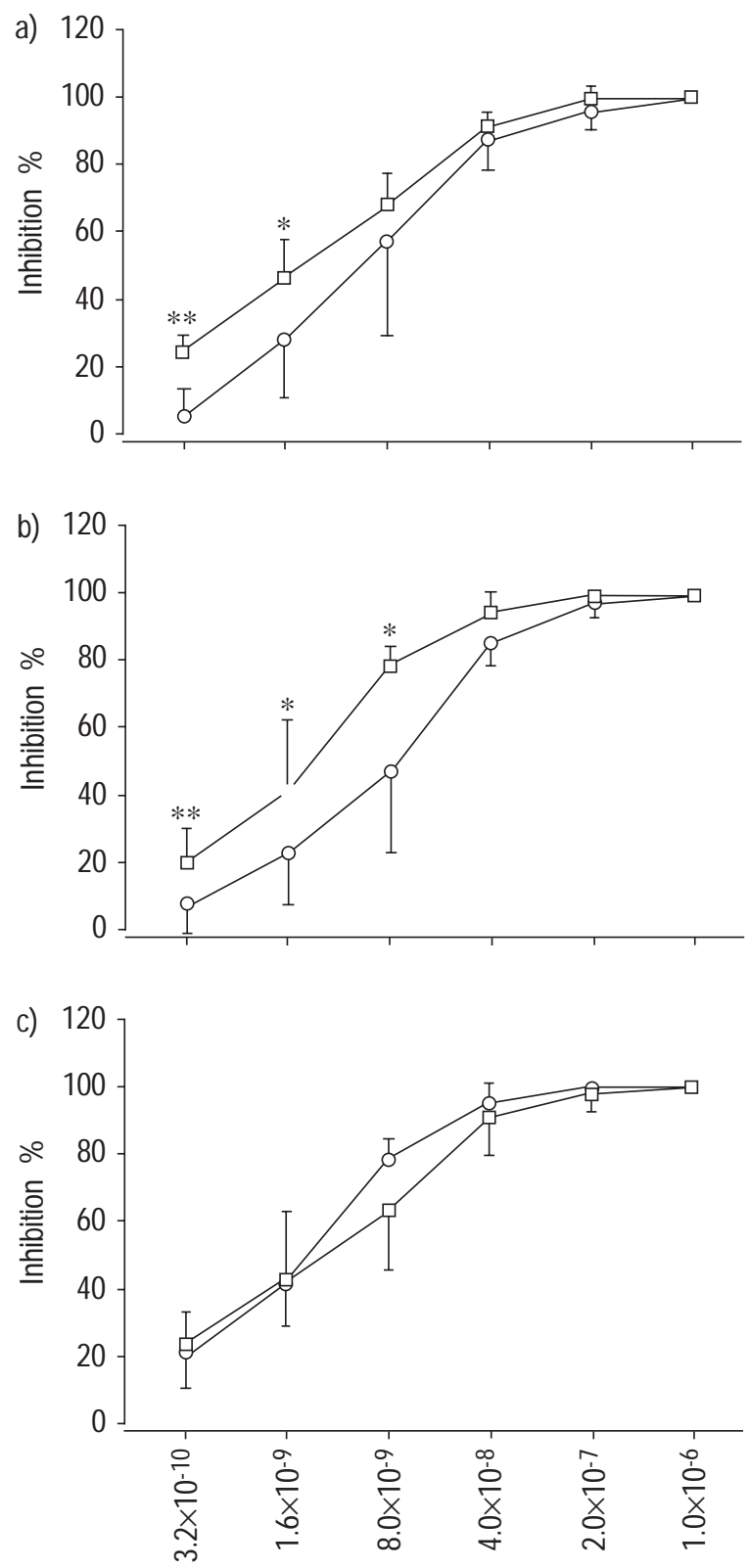

Dexamethasone $\mathrm{M}$

Fig. 1. - Mean ${ }^{3} \mathrm{H}$-thymidine incorporation by peripheral blood mononuclear cells (PBMCs) obtained from severe asthmatics and healthy control subjects in the presence of phytohaemagglutinin (PHA). a) Shows the decresed sensitivity of PBMCs to the anti-proliferative effects of dexamethasone in comparison to the normal control subjects, before methotrexate (MTX) treatment. $\bigcirc$ : asthmatics $(\mathrm{n}=8)$; $\square$ : control subjects $(n=8) ; *: p=0.03 ; * *: p=0.001$. b) Illustrates the left shift of the curve after MTX treatment indicating increased response of PBMCs to dexamethasone in vitro, in asthmatics. $\bigcirc$ : before MTX $(\mathrm{n}=6) ; \square$ : after $\operatorname{MTX}(\mathrm{n}=6) ; *: \mathrm{p}=0.04 ; * *: \mathrm{p}=0.02$. c) shows that the inhibition of PHAinduced proliferation of PBMCs by dexamethasone is not different between asthmatics after 8 weeks of MTX treatment and control subjects. $O$ : asthmatics $(\mathrm{n}=6) ; \square$ : control subjects $(\mathrm{n}=6)$. 
differences were noticed between control subjects and asthmatic subjects after treatment with MTX (fig. 1c). The results in the control subjects were not statistically different for any concentration of dexamethasone at both time points $(\mathrm{p}>0.05)$.

Dexamethasone induced proliferation inhibition of PBMC as well as flow cytometry of peripheral blood were also performed in the two patients who were withdrawn from the study 4 weeks after MTX was commenced. Both subjects (patient Nos. 7 and 8, table 1) showed a left shift of the curve after MTX which was similar to that of the six other asthmatics.

Effect of methotrexate treatment on numbers of inflammatory cells in bronchial biopsies

The results of immunohistochemistry of biopsies from the seven asthmatics are summarized in figure 2 and table 3. When biopsies obtained after MTX treatment were compared with the pretreatment biopsies, there was a significant increase in the median number of CD3+ Tcells from 50 to 81 cells $\cdot \mathrm{mm}^{-2}$ mucosa $(\mathrm{p}=0.04)$. Analyses of the serially-cut sections stained with antibodies direc-
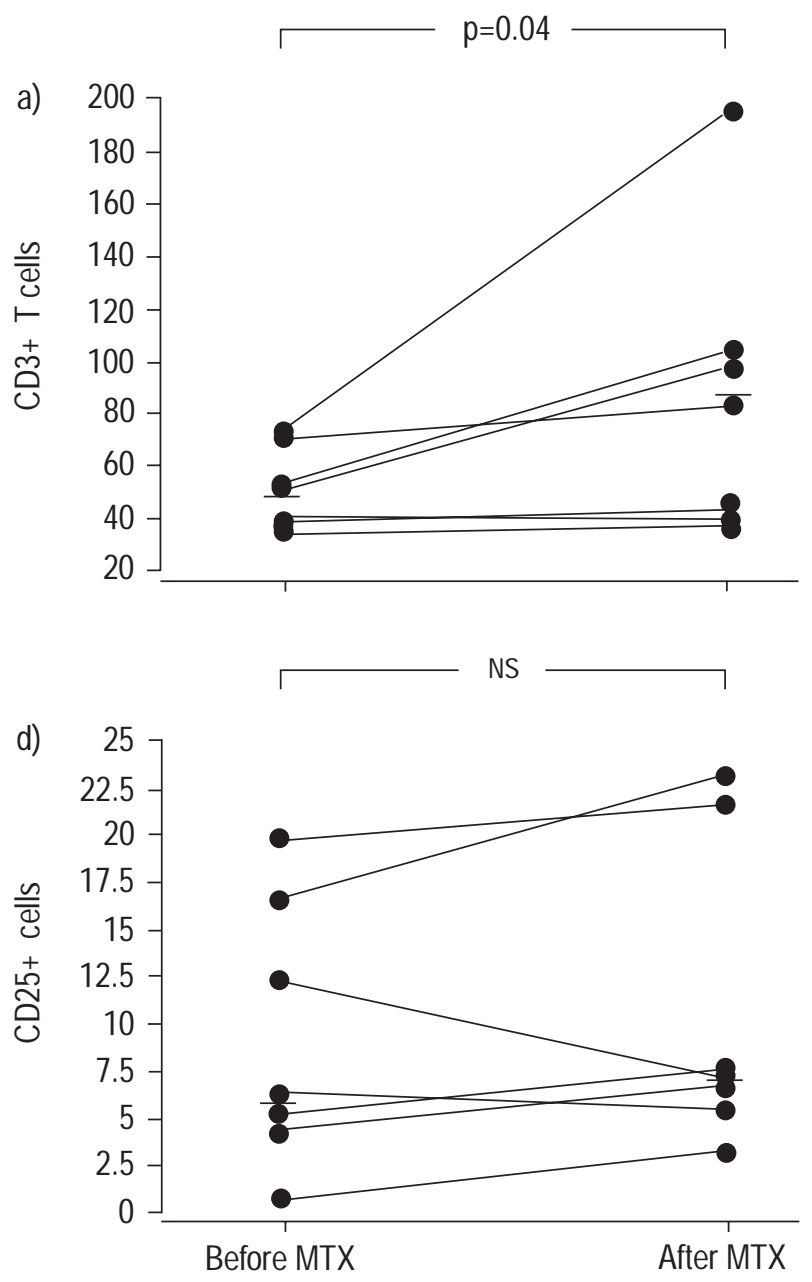

ted against CD3, EG2 and CD25 revealed that all CD25+ cells were T-cells. No significant changes were observed in the numbers of CD25+ cells, eosinophils, mast cells or neutrophils. Also the numbers of 4D9+ (intracellular IL4), 3H4+ (secretory IL-4) and Mab-7+ (IL-5) cells before and after MTX treatment revealed no significant differences.

\section{Effect of methotrexate on levels of free interleukin-8}

As shown in figure 3, MTX treatment was associated with a significant fall in the median levels of IL- 8 determined in eight subjects with severe asthma from 190 (range $10-1,684$ ) to $19 \mathrm{pg} \cdot \mathrm{mL}^{-1}$ (range $0-316 \mathrm{pg} \cdot \mathrm{mL}^{-1}$; $\mathrm{p}=0.03$ ). No significant correlations were found between changes in IL-8 levels and any of the clinical, blood or biopsy findings.

\section{Discussion}

In this open study the authors have shown that MTX treatment is associated with improvement of the in vitro sensitivity of PBMC to the inhibitory effects of dexamethasone. This supports the hypothesis that the potential

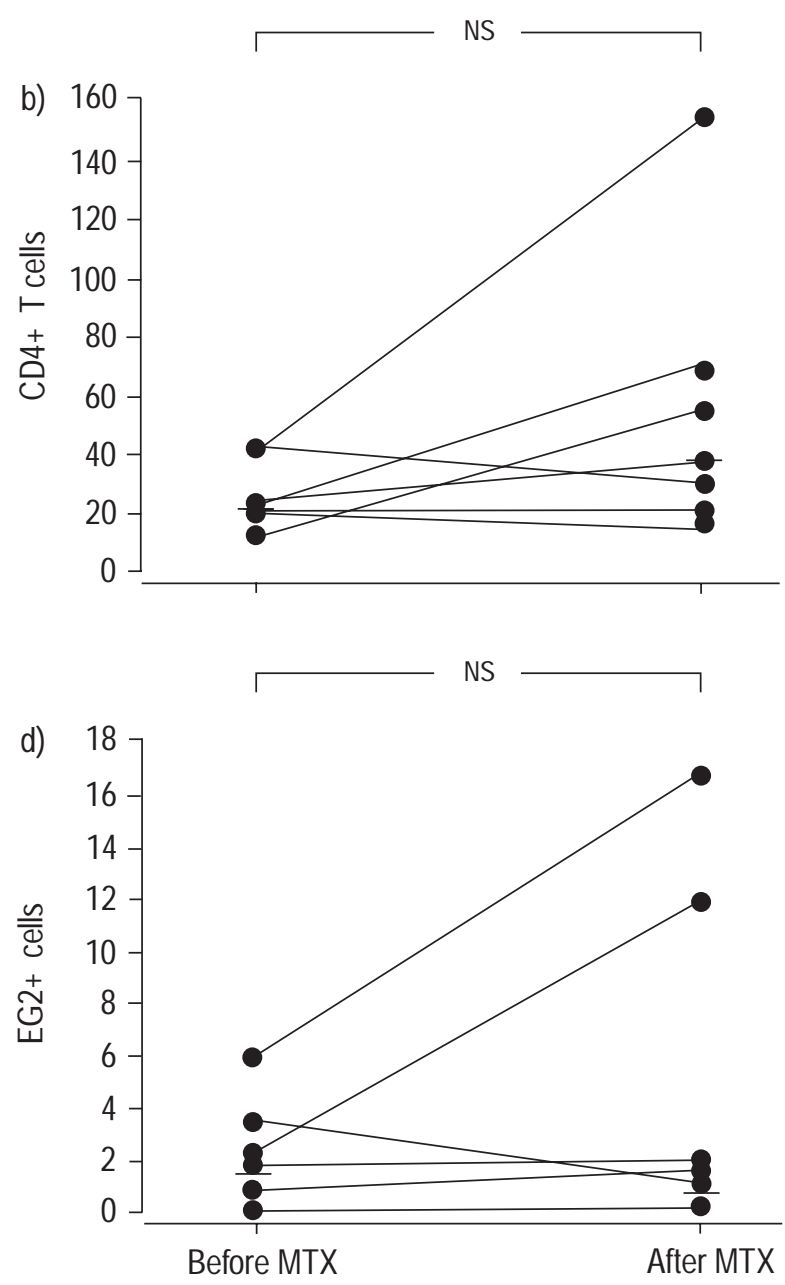

Fig. 2. - Effect of 8 week of methotrexate (MTX) treatment on numbers of T-cells (CD3; a), T-helper cells (CD4; b), the expression of the interleukin-2receptor $(\mathrm{CD} 25 ; \mathrm{c})$, and activated eosinophils (EG2; d) in bronchial biopsies from seven severe asthmatics. Results are expressed as numbers of cells per square millimetre submucosa. Horizontal bars represent median values. Individual values are given. 
Table 3. - Effects of methotrexate (MTX) treatment on inflammatory cells in bronchial biopsies $(n=7)$

\begin{tabular}{lccc}
\hline & Before MTX & After MTX & p-value \\
\hline CD3 & $50(35-74)$ & $81(35-192)$ & 0.04 \\
CD4 & $23(12-42)$ & $35(15-152)$ & 0.23 \\
CD8 & $13(7-34)$ & $34(5-119)$ & 0.34 \\
CD25 & $6.3(0.75-19.7)$ & $6.8(2.9-32.8)$ & 0.17 \\
EG2 & $1.7(0-5.9)$ & $1.4(0-16.4)$ & 0.27 \\
AA1 & $12(3-56)$ & $16(2-47)$ & 0.79 \\
NE & $22(9-30)$ & $39(9-112)$ & 0.17 \\
IL-4 (4D9) & $4.5(1.6-12.1)$ & $3.9(0-12.2)$ & 0.31 \\
IL-4 (3H4) & $2.4(0.8-10.6)$ & $10.1(0-24.4)$ & 0.40 \\
IL-5 (Mab-7) & $4.6(2.1-10.3)$ & $3.2(1.2-12.7)$ & 0.61 \\
\hline
\end{tabular}

Number of cells per square millimetre submucosa, expressed as median (range). NE: antineutrophil elastase; IL: interleukin.

benefit of MTX may result from increased sensitivity of Tcells to the inhibitory effects of glucocorticoids. However, there was no evidence for any additional anti-inflammatory effects of MTX in peripheral blood and endobronchial biopsies and, except for a decrease in serum IL-8, treatment with MTX was not associated with a reduction in the numbers of inflammatory cells or their state of activation in vivo.

A number of open studies has suggested clinical efficacy of MTX $[10,11]$. This has been confirmed in doubleblind placebo-controlled trials $[12,13]$. One criticism of the present clinical observations is that the study was open-label without a placebo control group and was too short to draw conclusions with regard to the clinical effects of MTX [9]. However, the main goal of this study was to determine the mechanism by which MTX might improve asthma control and reduce glucocorticoid-dependency, and to assess possible inhibitory effects on those parameters that are relevant to the pathophysiology of severe asthma.

Glucocorticoids and MTX are often used together, but they differ in regard to their effects on leukocyte recruitment and mediator release. Both in vitro and in vivo studies have presented substantial evidence that glucocorticoids inhibit T-cell activation and the release of IL-3, IL-4, IL5 and granulocyte-macrophage colony-stimulating factor

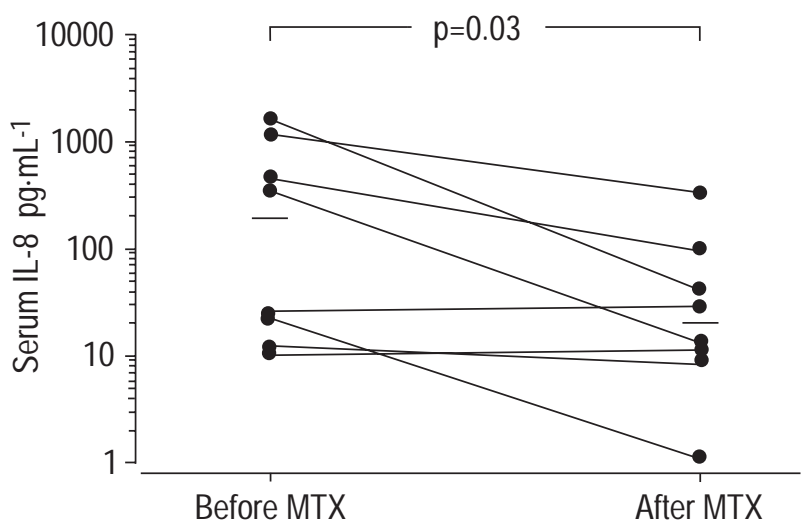

Fig. 3. - Effect of combined glucocorticoid and methotrexate (MTX) treatment on serum levels of free interleukin (IL)- 8 in eight subjects with glucocorticoid-dependent asthma. Horizontal bars represent median values. Individual values are given.
(GM-CSF), cytokines that are involved in mast cell and eosinophil recruitment and activation [3]. Two possible, immunosuppressive and anti-inflammatory, mechanisms of MTX should be considered. An immunosuppressive action secondary to the interference of MTX with folatedependent nucleic acid synthesis is consistent with its effects in cancer chemotherapy, but blocking of deoxyribonucleic acid (DNA) synthesis is not evident with low doses of MTX (5-25 mg.week ${ }^{-1}$ [9]. An anti-inflammatory mode of action is supported by a number of studies showing reduced neutrophil-dependent inflammation, IL1 production of mononuclear cells, basophil histamine release, and platelet activating factor (PAF)-induced eosinophil chemotaxis $[16,17,25]$. In contrast numbers of mononuclear cells, mast cells and neutrophils present in the synovium from patients with rheumatoid arthritis are unchanged following treatment with low-dose MTX [16]. From these observations it has been suggested that MTX is an agent that interferes with cell function but not cell number.

Consistent with previous observations [4], the refractoriness of PBMC from the current patients to dexamethasone inhibition underlines their relative glucocorticoid-insensitivity. It is unlikely that the chronic use of systemic glucocorticoids in these patients is responsible for this observation because after 8 weeks of treatment with MTX, during which the dose of glucocorticoids remained unaltered, the unresponsiveness of PBMC to dexamethasone was completely abrogated. The observation that the sensitivity of PBMC from healthy control subjects on two separate occasions did not differ, indicates that the current in vitro assay is reproducible. Because MTX inhibits the enzyme thymidylate synthetase the in vitro response of the cells to MTX could not be determined using this assay. MTX creates a cellular deficit of thymidylate resulting in increased cellular avidity for uptake of tritiated thymidine when it is added to cells exposed to MTX [25].

There has been increasing interest recently with regard to the mechanisms that are involved in the pathogenesis of severe asthma. Several studies support the concept that glucocorticoid-resistant asthma is associated with persistent T-cell activation and airway inflammation and is thought to be the result of a decreased glucocorticoid-receptor affinity $[5,26]$. It has been proposed that cytokineinduced overexpression of transcription factors, such as activating protein (AP)-1 and nuclear factor (NF)- $\mathrm{kB}$, is responsible for the decreased glucocorticoid responsiveness in these patients [27]. The observation that glucocorticoid sensitivity could be restored after MTX treatment suggests that MTX enhances the sensitivity of PBMC to glucocorticoids which may explain its steroid-sparing effect which was not investigated in this study. This raises the possibility that the glucocorticoid-sparing effect of MTX can be attributed to its potential to reverse the glucocorticoid refractoriness through interference with the release of mediators involved in decreased glucocorticoid responsiveness. This is in agreement with observations in clinical trials where the addition of MTX to antiasthma treatment is associated with reduction of glucocorticoid requirements, but not improvement of bronchial hyperresponsiveness or pulmonary function, compared to baseline values or placebo [9-13]. Although the authors have not assessed the effect of low-dose MTX on prednisolone clearance in their patients, the possibility that MTX 
affects glucocorticoid metabolism can largely be discounted because in many trials oral glucocorticoids could be discontinued in subjects with severe asthma [10-12].

The in vitro observations in this study prompted the authors to investigate the effect of MTX on mucosal inflammation in biopsies obtained from patients with poorlycontrolled glucocorticoid-dependent asthma. Although it concerned another group, they were clinically not different from the subjects who participated in the in vitro study. Addition of MTX did not lead to a decrease in circulating and mucosal T-cells or their state of activation, and compared to baseline values the number of CD3+ T-cells in the mucosa were even increased after treatment. Whether this increase in T-cells implicates a positive response to MTX treatment is difficult to tell because a positive clinical response is generally seen after 24 weeks [9]. Similar observations have been made in synovia biopsies from patients with rheumatoid arthritis which have shown that MTX treatment induces an improvement in clinical and serological indices of disease activity but is not associated with a decrease in the inflammatory infiltrate in the synovia [28]. In addition, the density of the mononuclear cell infiltrate is higher in the synovial membranes from patients with rheumatoid arthritis treated with MTX when compared to the specimens from patients receiving nonsteroidal anti-inflammatory drugs with no differences being observed in the numbers of T-cell subsets or IL-2 bearing cells between the groups [28]. The authors also have been unable to show any differences in mast cell numbers, eosinophilia or the numbers of IL-4 and IL-5 positive cells in the biopsies of these patients before and after MTX treatment. In an animal model of adjuvant arthritis it has been found that MTX improves the ability of lymphocytes to synthesize IL-2 [29]. Also in patients with rheumatoid arthritis increased levels of IL-2 have been found during MTX treatment [30]. If this mechanism is also operative in severe asthma, it could explain the increase in CD3+ T-cells observed in the biopsies from the current patients. As mentioned above, these observations are in line with those made in rheumatoid arthritis where MTX dramatically diminishes inflammation without affecting the accumulation of inflammatory cells $[16,17]$ which further supports the concept that in asthma lowdose MTX exerts its effects as an immunomodulator agent that affects cell function rather than cell number. It is suggested that future studies should focus on the effect of MTX on cell activity by analysing the production and release of mediators, such as IL-8, that are relevant to asthma pathogenesis before and after treatment.

Recent published work has shown increased levels of free IL-8 in serum from severe glucocorticoid-dependent asthmatics, whereas no IL- 8 could be detected in mild asthmatics or healthy control subjects [7]. In subjects with rheumatoid arthritis it has been demonstrated that the production of IL-8 by PBMC is inhibited by MTX [31], suggesting that MTX is a potent anti-inflammatory drug. However, unlike glucocorticoids, MTX does not exhibit any effect on the release of IL-1, $-2,-4,-5$, or -8 by T-cells in vitro [32]. Based on the results of the present in vitro observations, it is therefore possible that the observed decrease in levels of free IL- 8 may be attributed to the enhanced inhibitory effect of glucocorticoids on T-cells. Although PBMC may produce significant amounts of this chemokine, a direct inhibitory effect on other cells cap- able of producing IL-8, such as epithelial cells, fibroblasts and mast cells, cannot be excluded [33]. Further studies on the in vitro effects of MTX on the production of IL-8 and other mediators by these cells are required.

The clinical deterioration of asthma, resembling MTXinduced asthma [34], observed in one patient after MTX was commenced, occurred despite improved responsiveness of T-lymphocytes to the antiproliferative effects of dexamethasone after 4 weeks of treatment. Although an increase in peripheral blood T-cell activation was noted in this patient, it is unlikely that the attacks were solely provoked by an abundant inflammatory response, especially because increasing the dose of glucocorticoids did not relieve the symptoms. In rheumatoid arthritis, it has been demonstrated that the beneficial effect of MTX is related to an increased release of the autocoid adenosine that exerts an anti-inflammatory effect through binding to its A2-receptor [16]. However, in asthma adenosine is a potent bronchoconstrictor probably due to activation of mast cells via A2-receptors [35]. In clinical trials conducted so far [11], the absence of reduced, and incidentally even increased, bronchial hyperresponsiveness following MTX treatment might be associated with increased release of adenosine, and explain the clinical deterioration observed in this patient. This raises the possibility that the final outcome of MTX treatment in glucocorticoid-dependent asthmatics, therefore, may depend on the balance between improved responsiveness to the suppressive action of glucocorticoids and the degree of MTX-induced autocoid release. To test this hypothesis further investigations into the nature and dynamics of these events are needed and may be helpful to distinguish "MTX-responders" from "nonresponders".

In summary, this study demonstrates that low-dose methotrexate may be a useful substitute to glucocorticoid therapy in some but not all severe asthmatics. It has been shown that the glucocorticoid sensitivity returns to normal after short-term treatment with methotrexate, which may explain its steroid-sparing properties. In accordance with observations made in patients with rheumatoid arthritis $[16,17,28]$, the absence of a clear quantitative anti-inflammatory effect in severe asthma suggests that methotrexate exerts its effect by modulation of cell function rather than cell number.

Acknowledgements. The authors like to thank the Swiss Institute for Allergy and Asthma Research for their technical assistance in performing the in vitro assays.

\section{References}

1. Djukanovic R, Roche WR, Wilson JW, et al. Mucosal inflammation in asthma. Am Rev Respir Dis 1990; 142: 434-457.

2. Djukanovic R, Wilson JW, Britten KM, et al. Effect of an inhaled corticosteroid on airway inflammation and symptoms in asthma. Am Rev Respir Dis 1992; 145: 669-674.

3. Robinson D, Hamid Q, Ying S, et al. Prednisolone treatment in asthma is associated with modulation of bronchoalveolar lavage cell interleukin-4, interleukin-5, and interferon-gamma cytokine gene expression. Am Rev Respir Dis 1993; 148: 401-406. 
4. Corrigan CJ, Brown PH, Barnes NC, et al. Glucocorticoid resistance in chronic asthma. Glucocorticoid pharmacokinetics, glucocorticoid receptor characteristics, and inhibition of peripheral blood T cell proliferation by glucocorticoids in vitro. Am Rev Respir Dis 1991; 144: $1016-1025$.

5. Corrigan CJ, Brown PH, Barnes NC, Tsai JJ, Frew AJ, Kay AB. Glucocorticoid resistance in chronic asthma. Peripheral blood $\mathrm{T}$ lymphocyte activation and comparison of the T lymphocyte inhibitory effects of glucocorticoids and cyclosporin A. Am Rev Respir Dis 1991; 144: 10261032.

6. Vrugt B, Wilson S, Underwood J, et al. Mucosal inflammation in severe glucocorticoid-dependent asthma. Eur Respir J 1999; 13: 1245-1252.

7. Shute JK, Vrugt B, Lindley IJ, et al. Free and complexed interleukin-8 in blood and bronchial mucosa in asthma. Am J Respir Crit Care Med 1997; 155: 1877-1883.

8. Lock SH, Kay AB, Barnes NC. Double-blind, placebocontrolled study of cyclosporin A as a corticosteroidsparing agent in corticosteroid-dependent asthma. $\mathrm{Am} \mathrm{J}$ Respir Crit Care Med 1996; 153: 509-514.

9. Marin MG. Low-dose methotrexate spares steroid usage in steroid-dependent asthmatic patients: a meta-analysis. Chest 1997; 112: 29-33.

10. Mullarkey MF, Lammert JK, Blumenstein BA. Longterm methotrexate treatment in corticosteroid-dependent asthma. Ann Intern Med 1990; 112: 577-581.

11. Shiner RJ, Katz I, Shulimzon T, Silkoff P, Benzaray S. Methotrexate in steroid-dependent asthma: long-term results. Allergy 1994; 49: 565-568.

12. Mullarkey MF, Blumenstein BA, Andrade WP, Bailey GA, Olason I, Wetzel CE. Methotrexate in the treatment of corticosteroid-dependent asthma. A double-blind crossover study. N Engl J Med 1988; 318: 603-607.

13. Shiner RJ, Nunn AJ, Chung KF, Geddes DM. Randomised, double-blind, placebo-controlled trial of methotrexate in steroid-dependent asthma. Lancet 1990; 336: 137-140.

14. Weinblatt ME, Coblyn JS, Fox DA, et al. Efficacy of lowdose methotrexate in rheumatoid arthritis. $N$ Engl J Med 1985; 312: 818-822.

15. Ternowitz T, Bjerring P, Andersen PH, Schroder JM, Kragballe K. Methotrexate inhibits the human C5ainduced skin response in patients with psoriasis. J Invest Dermatol 1987; 89: 192-196.

16. Cronstein BN. Molecular mechanism of methotrexate action in inflammation. Inflammation 1992; 16: 411-423.

17. Cronstein BN, Weissmann G. Targets for antiinflammatory drugs. Annu Rev Pharmacol Toxicol 1995; 35: 449462.

18. Standards for the diagnosis and care of patients with chronic obstructive pulmonary disease (COPD) and asthma. American Thoracic Society. Am Rev Respir Dis 1987; 136: 225-244.

19. Ryan G, Latimer KM, Dolovich J, Hargreave FE. Bronchial responsiveness to histamine: relationship to diurnal variation of peak flow rate, improvement after bronchodilator, and airway calibre. Thorax 1982; 37: 423-429.

20. Aalbers R, de Monchy JG, Kauffman HF, et al. Dynamics of eosinophil infiltration in the bronchial mucosa before and after the late asthmatic reaction. Eur Respir J 1993; 6: 840-847.

21. Djukanovic R, Wilson JW, Lai CWK, Holgate ST, Howarth PH. The safety aspects of fibreoptic bronchoscopy, bronchoalveolar lavage, and endobronchial biopsy in asthma. Am Rev Respir Dis 1991; 143: 772-777.

22. Britten KM, Howarth PH, Roche WR. Immunohistochemistry on resin sections: a comparison of resin embedding techniques for small mucosal biopsies. Biotech Histochem 1993; 68: 271-280.

23. Bradding $\mathrm{P}$, Feather $\mathrm{IH}$, Howarth $\mathrm{PH}$, et al. Interleukin-4 is localised to and released by human mast cells. $J$ Exp Med 1992; 176: 1381-1386.

24. McNamee LA, Fattah DI, Baker TJ, Bains TJ, Hissey PH. Production, characterisation and use of monoclonal antibodies to human interleukin 5 in an enzyme-linked immunosorbent assay. J Immunol Methods 1991; 141: 81-88.

25. Tsai JJ, Wang TJ, Wang SR. The inhibitory effect of methotrexate on PAF-induced neutrophil and eosinophil locomotion in asthmatic patients. Asian Pac J Allergy Immunol 1994; 12: 65-71.

26. Sher ER, Leung DY, Surs W, et al. Steroid-resistant asthma. Cellular mechanisms contributing to inadequate response to glucocorticoid therapy. J Clin Invest 1994; 93 : 33-39.

27. Barnes PJ, Adcock IM. Steroid resistance in asthma. QJM 1995; 88: 455-468.

28. Haraoui B, Pelletier JP, Cloutier JM, Faure MP, Martel Pelletier J. Synovial membrane histology and immunopathology in rheumatoid arthritis and osteoarthritis. In vivo effects of antirheumatic drugs. Arthritis Rheum 1991; 34: 153-163.

29. Ridge SC, Rath N, Galivan J, Zabriske J, Oronsky AL, Kerwar SS. Studies on the effect of D-penicillamine, gold thioglucose and methotrexate on streptococcal cell wall arthritis. J Rheumatol 1986; 13: 895-898.

30. Kremer JM, Lawrence DA. Correlation of immune parameters with clinical and laboratory effects in a prospective cohort of patients with rheumatoid arthritis receiving methotrexate. Arthritis Rheum 1992; 35: 144.

31. Seitz M, Dewald B, Ceska M, Gerber N, Baggiolini M. Interleukin-8 in inflammatory rheumatic diseases: synovial fluid levels, relation to rheumatoid factors, production by mononuclear cells, and effects of gold sodium thiomalate and methotrexate. Rheumatol Int 1992; 12: $159-164$.

32. Schmidt J, Fleissner S, Heimann Weitschat I, et al. Effect of corticosteroids, cyclosporin A, and methotrexate on cytokine release from monocytes and T-cell subsets. Immunopharmacology 1994; 27: 173-179.

33. Kunkel SL, Standiford T, Kasahara K, Strieter RM. Interleukin-8 (IL-8): the major neutrophil chemotactic factor in the lung. Exp Lung Res 1991; 17: 17-23.

34. Jones G, Mierins E, Karsh J. Methotrexate-induced asthma. Am Rev Respir Dis 1991; 143: 179-181.

35. Polosa R, Ng WH, Crimi N, et al. Release of mast-cellderived mediators after endobronchial adenosine challenge in asthma. Am J Respir Crit Care Med 1995; 151: 624-629. 